\title{
Editorial for the Inaugural Special Issue on the Developing Trends of Power Electronics: Part 2
}

$\mathrm{W}$ ITH this editorial, we sincerely welcome our readers to the brand-new publication - CPSS Transactions on Power Electronics and Applications (CPSS TPEA). It is sponsored and published by China Power Supply Society (CPSS) and technically co-sponsored by IEEE Power Electronics Society (IEEE PELS).

CPSS was founded in 1983 and has been the only top-level national academic society in China that solely focuses on the power supply/power electronics area. In the past 30plus years CPSS has dedicated to provide to its members, researchers, and industry engineers nationwide with high quality services including conferences, technical training, and various publications, and this in deed has helped the society build up its membership rapidly, which now totals up to more than 4000 individual members plus 500 enterprise members. The fast growth of membership in turn compels CPSS to always work out better services for its members, one of which being the open-up of this periodical — a new journal in English language as a publication platform for international academic exchanging. This of course needs to be done through international cooperation, and that's why IEEE PELS is tightly involved, being the premier international academic organization in power electronics area and one of the fastest growing technical societies of the Institute of Electrical and Electronics Engineers (IEEE).

To fulfill the publishing need of the fast-developing power electronics technology worldwide is a more important purpose of launching this new journal. So far there are only 3 or 4 existing journals which are concentrated on power electronics field and have global reputation. For quite a few years people in the international power electronics community have had the feeling that, the existing journals have not even come close to meeting the huge demand of global academic and technology exchanges. E.g., the two existing IEEE power electronics journals, i.e. IEEE Transactions on Power Electronics (IEEE TPEL) and IEEE Journal of Emerging and Selected Topics in Power Electronics (IEEE JESTPE), now publish about 1000 papers a year, which is under a very low paper acceptance rate of around $25 \%$, but still have a back-log of about one year for the newly accepted papers to finally appear in printed form to the public. The addition of this new dedicated journal would be an ideal improvement to fulfill such a tremendous need.

The booming of publishing need really is an indicator of how fast power electronics has been developing in recent years. Innovations have been continuously coming up from

Digital Object Identifier 10.24295/CPSSTPEA.2017.00001 component (both active device and passive device), module, circuit, converter, to system level, covering different technical aspects as topology or structure conceiving, modeling and analysis, control and design, and measurement and testing. New issues and corresponding solutions have been continuously presenting as the applications of power electronics prevail horizontally in almost every area and corner of human society, from industry, residence and commerce, to transportations, and penetrate vertically through every stage of electric energy flow from generation, transmission and distribution, to utilization, in either a public power grid or a stand-alone power system. I personally believe that we are entering a world with "more electronic" power systems. The prediction around 30 years ago, that power electronics one day will become one of the major poles supporting the human society, is coming into reality. And I also believe, that power electronics is going to last for long time as an important topic since it is one of the keys to answer a basic question for human society, which is how human can harness energy more effectively and in a manner friendlier to both the user and the environment.

Therefore, I assume that there is probably no better fitting as for CPSS TPEA to publish its first few issues under a special topic about the developing trends of power electronics. We have invited a group of leading experts in different areas of power electronics to write survey/review papers or special papers with review/overview nature to some extent. To publish in a timely and regular style, we organize this inaugural Special Issue into different parts. Part 1 was published in the December issue last year, Part 2 appears in this March issue, and the following parts are scheduled for the next issues.

In Part 2 we are honored to have 8 invited papers. For the first 3 , each addresses one hot topic respectively in one of the 3 major application areas of power electronics: electric power grid, motor drives, and power supplies. The next 3 follow up with the state-of-the-arts in the structure or converters that are adopted in data center power systems, while the last 2 discuss specific issues for general power electronic circuits and systems.

We begin with a paper on the modernization of electric power grid. It is co-authored by Dr. Don Tan and Dr. Damir Novosel representing leadership of IEEE Power Electronics Society and IEEE Power and Energy Society respectively. It presents how power electronics \& systems (PEAS) technology could possibly provide smart technology solutions for the power grid modernization to meet the grand energy challenge.

The second paper reviews the technology, research, and 
applications of switched reluctance drives (SRD). It is written by Dr. Rik W. De Doncker and his research group from RWTH Aachen University, and presents a broad overview of the SRD taking into consideration all aspects such as machine modeling, design, control development, applications on the market and the focus of current research.

The third paper is about very high frequency (VHF) power converters. It is written by Dr. Dianguo Xu and his research group from Harbin Institute of Technology. It starts from the application background, introduces different topologies, and discusses resonant driving and control methods in a survey form.

The fourth paper is regarding data center challenges and their power electronics solutions. It is written by Dr. Philip T. Krein from the University of Illinois at Urbana-Champaign. The paper reviews the power hierarchy levels within modern data centers, and considers energy consumption and power electronics challenges across all levels of a data center, including building distribution, dc architectures, and conversion down to the board level.

The fifth paper is written by Dr. Johann W. Kolar and his research group from ETH Zurich, discussing techniques to realize highly efficient rectifier with minimized life cycle cost in DC data centers. It demonstrates how semiconductor technology, chip area, magnetic component volumes and switching frequency can be selected based on life cycle cost using analytical and numerical optimizations, and can be applied to three-phase buck-type PFC rectifier with integrated active filter for 380V DC distribution systems.

The sixth paper is written by Dr. Yan-Fei Liu and his research group from Queen's University, discussing LLC converter with possible application in data center, telecom, PV, and battery charging etc. It provides a comprehensive review on the latest advances of LLC converter from the perspective of topology and control with techniques range from high current, fast dynamic response to wide operational voltage range.

The seventh paper is written by Dr. Bo Zhang from the South China University of Technology, about sneak circuit - the unexpected path or operational status in an electric or electronic circuit due to the limitation or oversight in design. The paper briefly reviews sneak circuits in power converters and corresponding analyzing methods, with some interesting application examples.

Last but not least, the eighth paper is written by Dr. Chi $\mathrm{K}$. Tse and his research group from Hong Kong Polytechnic University, revisiting stability criteria for DC power distribution systems. The paper focuses on the stability of current-source converter systems through an impedance-based approach, where a general set of stability criteria is developed and experimentally verified.

I'd like to thank the authors of all these 8 invited papers. It's their high-quality contributions that finally leads to the launching of this new journal. I'd like to thank Dehong Xu, President of CPSS, who in 2015 initiated the idea of publishing the new journal and since then has been persistently supporting my work as the founding Editor-in-Chief. I'd also like to thank Jiaxin Han, Secretary General of CPSS, Jan A. Ferreira, President of IEEE PELS, 2015-2016, Don F. D. Tan, President of IEEE PELS, 2013-2014, and Frede Blaabjerg, IEEE PELS Vice President for Products, 20152018, who form the CPSS and IEEE PELS Joint Advisory Committee for our new journal with Dehong Xu and myself. Other IEEE officers and leading staffs like Dushan Borojevich, PELS President, 2011-2012, Alan Mantooth, PELS President, 2017-2018, Mike Kelly, PELS Executive Director, and Frank Zhao, Director of China Operations, IEEE Beijing Office, just to name a few, also provided continuous support and constructive advices. My earnest thanks also go to the CPSS Editorial Office led by Lei Zhang, Deputy Secretary General of CPSS, for their wonderful editing work. It would not have been possible to create a new journal in such a short time without their efforts. I'd like to finally thank all the members of the Executive Council of CPSS and particularly the leaders of Chinese power electronics industry. They always firmly stand behind CPSS TPEA and ready to help whenever needed.

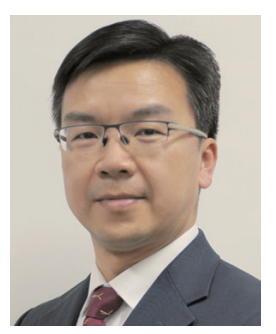

Jinjun LIU received his B.S. and Ph.D. degrees in Electrical Engineering from Xi'an Jiaotong University (XJTU), China in 1992 and 1997 respectively. He currently holds the position of XJTU Distinguished Professor of Power Electronics, sponsored by Chang Jiang Scholars Program of Chinese Ministry of Education.

Dr. LIU coauthored 3 books (including a textbook), published over 200 technical papers in peer-reviewed journals and conference proceedings, and holds more than 30 invention patents (China/USA). He received for 7 times governmental awards at national level or provincial/ministerial level for scientific research achievements or academic/teaching career achievements. He also received the 2006 Delta Scholar Award, the 2014 Chang Jiang Scholar Award, the 2014 Outstanding Sci-Tech Worker of the Nation Award, and the IEEE Transactions on Power Electronics 2016 Prize Paper Award. His research interests are power quality control and utility applications of power electronics, micro-grids for sustainable energy and distributed generation, and more/all electronic power systems.

Dr. Liu has served as the IEEE Power Electronics Society (PELS) Region 10 Liaison and then China Liaison for 9 years, an Associate Editor for the IEEE Transactions on Power Electronics for 9 years, and starting from 2015 the Vice President for membership of IEEE PELS. He is on Board of China Electrotechnical Society (CES) and was elected to a Vice President of the CES Power Electronics Society in 2013. He is the Vice President for International Affairs, China Power Supply Society (CPSS) and the inaugural Editor-in-Chief of CPSS Transactions on Power Electronics and Applications. 